\title{
Analysis of the Causes of the Preschool Education Quality in China
}

\author{
Wu Hong \\ Xi’an International University, Xi’an, Shaanxi, China, 710076
}

Keywords: preschool education; quality; current situation; reason

\begin{abstract}
Preschool education is the second "parent" of young children's enlightenment. It is an elementary stage in the entire educational campaign. With the continuous deepening of the national education system reform, it has promoted the positive transformation of traditional score education concept. The entire education academic community has focused its attention on preschool education and has become the focus of much attention in all sectors of society. The main teaching goal of preschool education is to conduct various types of enlightenment education and basic education for children, provide theoretical support for children's future learning and social practice, and promote the comprehensive development of students' morality, intelligence, body and beauty ${ }^{[1]}$. This paper changes the background of the new class to a comprehensive analysis of the status quo of preschool education in China, discusses several outstanding issues, and resolves those issues through consultation.
\end{abstract}

\section{Introduction}

Preschool education is not a single entity in the process of development. It requires multiple schools, teachers, and parents to assist each other. The plans for various teaching activities can be completed and the children's intellectual development, thinking, and practice can be fully developed. Actively carrying out different models of preschool education in China has very important practical significance for the follow-up development of education. It can not only cultivate advanced and constructive talents for the national socialist cause, but also reserve a large number of socialist successors and contribute to comprehensive national strength. The comprehensive promotion promotes the country to develop in a more harmonious and healthy direction. It can be seen that understanding and mastering the current status of preschool education quality and basing on the scientific concept of development and digging deeper into the root causes of preschool education can quickly sum up an effective way to solve preschool education quality problems [2].

\section{The Importance of Preschool Education and its Development Significance}

On the one hand, the development of preschool education is the demand for the development of the nation's education as a whole. During the students' entire learning career, preschool education as a student enlightenment lays a solid foundation for students' knowledge, and at the same time, it also plays a positive role in promoting the development of the nation's education as a whole. Judging from the time frame of the entire education industry, preschool education preceded nineyear compulsory education, and it shoulders a major responsibility for popularizing basic theoretical knowledge and the quality of basic education. At this stage, it focused on cultivating and demonstrating student learning habits and learning interests. The students laid a solid foundation for adapting to the learning and life of primary schools as soon as possible. The enrollment rate of compulsory education has increased significantly, and the dropout rate has been reduced. It is of great significance to consolidate nine-year compulsory education and other types of education and accelerate the construction of a lifelong education system.

On the other hand, the development of preschool education plays an important role in family and social development. The full implementation of the new family planning policy has greatly promoted the development and transformation of the national economy and the concept of education. Preschool education has become an important content for parents and the society. At 
present, the proportion of one-child families in China is larger in the total household population. Children's learning process is healthy and has a profound impact on the whole family. The focus of parents is not only on children's preschool education but also on the quality of preschool education, enhance children's future growth through quality education resources and education [3]. 0-3 years of age as a key stage of preschool education, young children in the relevant education institutions to accept system training, help parents to free their hands. Put personal energy and time into more meaningful social practices and promote the steady development of the country's overall economy.

\section{Comprehensive Analysis of the Present Situation of Preschool Education Quality in China}

\subsection{Lack of enough attention to preschool education from the state}

At the current stage, due to the consideration of the steady development of the national education cause, relevant departments have carried out a series of reforms and innovations in the educational model, educational philosophy, and education methods. Among them, compulsory education and college education reform are the main factors, while preschool education reform is less powerful than both. With the continuous improvement and optimization of the market economy system, we have built a model of economic development that is a national feature. Marketization has become a general trend of preschool education, which has given commercial features to preschool education. Preschool education institutions are in short supply, and to a certain extent, preschool education completely loses its own attributes [4]. In addition, compared to private teaching institutions, the proportion of private kindergartens in the total number has reached about $72 \%$, and the access of state policy agencies has widened the gap between the two and even led to the loss of survivability of many public kindergartens. From the management point of view, the government's supervision and management work has not yet reached private kindergartens, which has caused a large number of non-standard behaviors in the park, hindering the overall improvement of the overall quality of preschool education. Therefore, relevant government departments should further strengthen the supervision of private kindergartens, improve the various management and supervision mechanisms within the park, and lay a good foundation for the improvement of preschool education quality.

\subsection{The small size of the school and the imperfect hardware facilities}

At present, parents and even the whole society have a one-sided understanding of preschool education. They confuse the actual connotation of preschool education with early childhood education. With the large-scale and quantitative development of preschool education institutions, the degree of complexity and difficulty of school enrollment work has been virtually increased [5]. In addition, the status quo of school hardware and software configuration, as well as the overall teaching environment conditions, may have a certain impact on the quality of preschool education. The comprehensive implementation of preschool education should closely focus on the characteristics of students' psychology and individuality, attach importance to cultivating interest in learning, and practice innovative spirit. While helping students to broaden their knowledge of eyeopening growth, they should also add more courses of interest, such as poetry recitation, hosting, music, Fine arts, dance and other art courses encourage students to understand their own characteristics of interest and professional direction, effectively promote the overall improvement of students' thinking ability and logic ability and allow students to cultivate interests and hobbies is to lay a solid foundation for the future. However, at present, the vast majority of preschool education institutions have relatively low teaching facilities, lack of a complete capital chain, and a serious shortage of funds. The schools are unable to carry out various interest courses on time, which hinder the development of students' personality and comprehensive development. Especially in remote rural areas, there are few interest classes and other types of courses. The old facilities are difficult to meet the needs of the modern talent market, and preschool education is relatively backward.

\subsection{Excessively extreme teaching content}

On the whole, preschool education is still at the primary development stage in domestic 
education. There is a lack of standardization in the setting of teaching content and the definition of teaching scope. Teaching content as the main body of educational activities, lack of clear provisions in pre-school education, to a large extent leading to preschool education in the setting of teaching content on the extreme phenomenon. On the one hand, some preschool education institutions modeled the content of early education courses on the setting of teaching content, such as simple content such as classroom games, extracurricular activities, singing and dancing, eating and living, lack of preschool education awareness, loss of preschool education implementation significance, and the overall teaching level stays in the early childhood education stage, this phenomenon in some small and medium-sized towns or rural preschool education in the performance of more obvious, blurred the concept of preschool education and early childhood education. On the other hand, pure knowledge supplementation is also a relatively extreme educational method in preschool education. This kind of interweaving of primary school mathematics, Chinese, English and other curriculum knowledge content and preschool education content interweaves, although, in a sense, it broadens the scope of students' cognitive scope and knowledge reserve, it runs counter to the actual educational needs of preschool children, which is not conducive to the comprehensive development of students' learning and life in the future.

\subsection{The imperfect relevant laws and regulations for preschool education}

Some of the more advanced countries in the world have listed preschool education as a national key education project and added a series of laws and regulations for preschool education to provide students with perfect legal protection for preschool learning and development. Taking the United States as an example, the Early Childhood Education and Development Law is a prescriptive provision for preschool education. Its role in practical applications is similar to that of the law. It provides effective legal protection for the education of preschool children. Looking at the domestic legal system, the legal regulation related to preschool education only includes the Kindergarten Management Regulations Through observation, the regulations lack practical guidance in the practical application process and cannot guarantee the preschool education teaching activities successfully launched. At present, the state has gradually introduced a series of new laws and regulations related to preschool education. However, from the point of view of overall content setting and management, it still needs to be constantly optimized and improved.

\section{The Main Reason Leading to Frequent Problems in Preschool Education}

First, kindergarten itself cannot take into account multiple aspects. Due to the consideration of multiple factors, preschool education institutions cannot effectively balance the balance between teaching quality and admission price. If the price is set too high and does not fall within the economic capacity of most households, it will affect the number of enrollment in institutions. The smooth development of pre-primary education requires the active cooperation of teachers, parents, and students. The strength of a single school alone is not enough to achieve the purpose of preschool education, and the poor employment prospects of preschool education, many preschool education teachers have chosen to upgrade. Therefore, the preschool education profession in the market lacks excellent teacher resources, and the salaries requirements are higher than the average teacher standards. Compared with large-scale preschool education institutions, small-sized educational institutions generally have low input costs and low teaching standards, and they still cannot meet the needs of parents.

Second, families have low requirements for preschool education. From the parents' point of view, more of it is hope and preschool institutions, and the two sides jointly share the responsibility of childcare. Compared with basic teaching conditions such as kindergarten hardware facilities, parents are more focused on the child's daily living and other trivial hours. The attitude of laissezfaire has greatly stimulated the popularity of private kindergartens. Although private kindergartens

have great advantages in terms of tuition, food, rest, and care time, the disadvantages are the lack of a strong teacher force, and the level of professional skills and professional qualities of the main preschool teachers is relatively low. 
Third, all walks of life do not attach importance to the development of kindergartens. Regardless of preschool education institutions, parents, or other related organizations, the lack of comprehensive understanding of preschool education cannot fully understand the importance of preschool education. The lack of attention from parents and kindergarteners will lead to a decline in preschool education in both aspects. The lack of attention of the relevant departments will result in irrational planning and strong intervention guidance for preschool education as a whole. At the same time, supervision will not be sufficient. Without appropriate incentives and penalties, it will increase the slackness of kindergartens.

\section{Effective Strategies for Solving the Problem of Preschool Education in China}

\subsection{Parents should establish correct educational concepts and set expectations.}

"Best hope for a child to have a bright future" is the expectation of almost every Chinese parent, they have a high expectation for children and attempt to develop children into versatile geniuses, from astronomy to science and technology, and from literature to art. In recent years, the cost of preschool education in China has been high and has continued to rise. Coupled with the overcultivation of highly educated people in today's society, the utilitarian tendency of "focus on interests " has become more common in modern education. Parents place too much emphasis on instilling systems knowledge and ignoring education for comprehensive abilities. From the perspective of educational psychology, respecting the autonomy of children's growth and guiding children to release their nature is the main purpose of educational activities. Based on the nature of education, it further explores the advantages of children and strictly follows the laws of children's physical and mental development. In addition, through all the details of daily life to guide children to carry out various activities, to ignite children's creative sparks, learn to respect others and care for others in the conduct of activities. The relevant experts explained that it is true that parents care for their children, but if they spoil them too much, it will affect the children's physical and mental development, which is not conducive to the formation of children's outstanding character. Combine with your child's own interests and interests and choose the right school together to ensure that your child builds their own social, communication, learning, living, and innovation skills in the kindergarten.

\subsection{Kindergartens must timely innovate management according to policy requirements to ensure the quality of education.}

At present, preschool institutions in China are mainly divided into two types: private and public, which should be based on the characteristics of both and promote the continuous integration of the two sides' advantages. With the impact of modern education concept, the traditional education concept has been shaken in the psychological status of parents and gradually Recognizing the importance of preschool education has virtually increased the demand for corresponding institutions. It not only puts forward corresponding improvement requirements for the humanistic spirit within the organization, but also proposes continuous innovation and reform in children's daily game activities. On the one hand, in accordance with the premise of the child's age development, follow the basic concepts and methods of preschool education, to carry out in-depth excavation and training of children's innovative ability and learning potential; On the other hand, children are encouraged to participate in physical exercise, and the spirit of unity and cooperation among children is fostered in the activities to enhance the spirit of collectivism. It is worth noting that the establishment of a balanced arts curriculum is not too much and not too little. The development of arts specialty courses is mainly to enable children to master more knowledge and basic theories during the game, and to train children's basic etiquette and basic literacy. To maximize the protection of preschool education teaching quality and teaching effectiveness. 


\subsection{Define government responsibilities to ensure that school-age children are admitted to kindergartens in time.}

The relevant government departments should step up the development of public kindergartens and strengthen the support for private kindergartens. Formulate a reasonable sharing mechanism for the cost of pre-primary education and determine the charge standard. In the construction of the teaching staff, it is necessary to grasp the standards of teacher admission, care about the problem of teacher treatment, strengthen the training of teachers' morality and the legal system after serving or pre-service posts, and improve the quality of preschool education teachers. From the national and government perspectives, we should increase the number of students, improve the quality of kindergartens, ensure that every school-age child enjoys the opportunity to receive pre-school education, effectively solve the problems of children's admission to the kindergarten and the expensive fee.

\subsection{Formulate policies to protect the professional quality of preschool education employees.}

Preschool education is a livelihood project of " preschool education ", and it is also a foundational project for the quality of all people. High-quality preschool education must rely on a team of early childhood teachers with a sense of well-being and professional qualities. On the one hand, it constantly improves the preschool teachers' wage protection mechanism, and increases the attractiveness of preschool teachers' occupations through kindergarten work age subsidies. On the other hand, it builds a stage for the growth of young teachers and enhances their sense of well-being and gain. In addition, preschool teachers should strive to break the shackles of the traditional education concept. Children are no longer merely passive recipients of knowledge but should become excellent students who can possess more knowledge, and they can accumulate learning experiences in the learning process and conclude a set of their own learning model. The main goal of the development of early childhood education activities is to improve children's overall learning ability and develop children's sense of responsibility, creativity, learning methods, and learning attitudes. Through many years of educational practice, the process of preschool education activities emphasizes that students are allowed to walk in the experience, measure with your feet, observe with your eyes, think with your heart, judge with your own mind, and express yourself in your own language.

\section{Conclusion}

In summary, during the continuous deepening of education reform work, the development of preschool education in the entire education industry was rejected. There are many problems in current preschool education. In reality, we should start from several aspects such as parents, preschool education institutions, government, and preschool teacher personnel. We must satisfy people's different needs for preschool education through a diverse school-building system. The healthy and orderly development of preschool education institutes is also a powerful supplement to the entire education undertaking.

\section{Acknowledgement}

Xi'an Social Fund Project in 2017, Status Analysis of Preschool Education and Study on its Development: Take Xi'an High-tech Zone of Economy for example Name Code:17IN16

\section{References}

[1] Binglin Zhong. To Develop Preschool Education, We Must Insist on The Importance of Popularization and Quality Improvement [J]. Chinese Journal of Education. 2014, 14(03):442-445.

[2] Lijun Yang, Jieqiong Hu, Shuhui Du. Research on the Present Situation and Countermeasures of the Quality of Kindergarten Group Teaching Activities: Taking Some Kindergartens in Hunan 
Province as an Example[J]. Teacher Education Research. 2013, 07(05): 275-278.

[3] Yahong Wang. Research on the Relationship Between the Concept of Kindergarten Teachers' Quality of Education and the Quality of Kindergarten Education [D]. Zhejiang Normal University. 2013.

[4] Yuan Gao. The Construction of Development Supervision Evaluation System for Kindergartens in Zhongshan District of Dalian City [D]. Liaoning Normal University 2013.

[5] Wang Biao. An Introduction to the Formation and Development of Preschool Education in China [D]. Fujian Normal University. 2016. 